\title{
Effects of Fiber Motion on the Acoustic Behavior of an Anisotropic, Flexible Fibrous Material
}

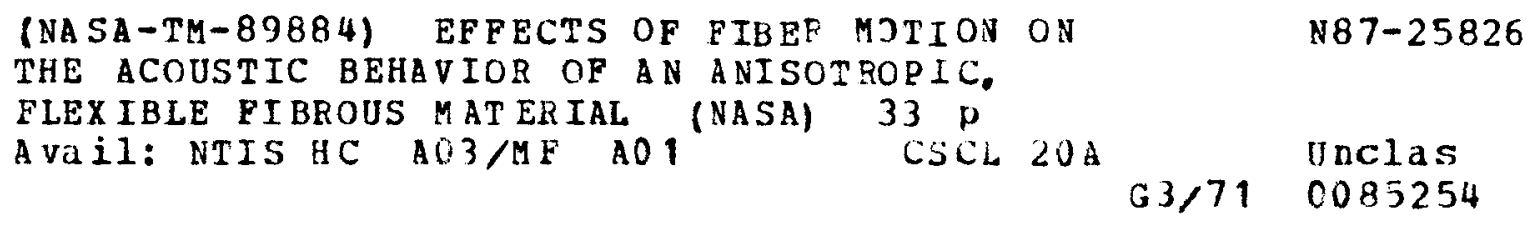

Milo D. Dahl, Edward J. Rice, and Donald E. Groesbeck Lewis Research Center

Cleveland, Ohio

Prepared for the

113th Meeting of the Acoustical Society of America Indianapolis, Indiana, May 11-15, 1987 
Trade names or manufacturers' names are used in this report for identification only. This usage docs not constitute an official endorsement, either expressed or implied, by the National Aeronautics and Space Administration. 


\section{EFFECTS OF FIBER MOTION ON THE ACOUSTIC BEHAVIOR OF AN ANISOTROPIC, FLEXIBLE FIBROUS MATERIAL \\ M1lo D. Dah1, Edward J. Rice, and Donald E. Groesbeck National Aeronautics and Space Administration Lewis Research Center Cleveland, Ohio 44135}

\section{ABSTRACT}

The acoustic behavior of a flexible fibrous material was studied experimentally. The material consisted of cylindrically shaped fibers arranged in a batting with the fibers primarily aligned parallel to the face of the batting. This type of material was considered anisotropic, with the acoustic propagation constant depending on whether the direction of sound propagation was parallel or normal to the fiber arrangement. Normal incidence sound absorption measurements were taken for both fiber orientations over the frequency range 140 to $1500 \mathrm{~Hz}$ and with bulk densities ranging from 4.6 to $67 \mathrm{~kg} / \mathrm{m}^{3}$. When the sound propagated in a direction normal to the fiber alignment, the measured sound absorption showed the occurrence of a strong resonance, which increased absorption above that attributed to viscous and thermal effects. When the sound propagated in a direction parallel to the fiber alignment, indications of strong resonances in the data were not present. From comparing these two sets of data and from considering the material structure, the resonance in the data for fibers normal to the direction of sound propagation was attributed to fiber motion. An analytical model was developed for the acoustic behavior of the material that displayed the same fiber motion characteristics shown in the measurements.

\section{LIST OF SYMBOLS}

ce effective propagation velocity in material, Eq. (A20)

co adlabatic speed of sound in air 
$c_{p}$ speciflc heat at constant pressure

$c_{v}$ specific heat at constant volume

$d$ fiber diameter $\left(1.254 \times 10^{-5} \mathrm{~m}\right)$

$H$ porosity, $1-\left(p_{b} / p_{f}\right)$

$h$ heat transfer coefficient

$1(-1)^{0.5}$

$K$ heat transfer parameter, Eq. (A14)

k complex propagation constant

$k^{\prime}$ thermal conductivity of air

$L$ depth of material

\& length of a fiber

p acoustic pressure

$p^{\prime}$ acoustic pressure in air incident on material

$p_{0}$ ambient air pressure

q fiber length with motion/total fiber length

$R$ gas constant

$r$ resistance coefficient of a flber

$T_{0}$ ambient alr temperature

$t$ time

$u$ acoustic particle velocity in the material

$u_{f}$ velocity of fiber motion

$\vec{u}$ volume velocity per unit area

$u^{\prime}$ acoustic particle velocity in air incident on material

$v_{f}$ volume of a fiber

W characteristic impedance

$x$ distance along $x$-axis 
acoustic impedance

$\alpha_{n}$ normal absorption coefficient

$\gamma$ ratio of specific heats, 1.4 for air

$\theta$ acoustic variation in temperature

$\mu \quad$ viscosity of air

$v \quad$ kinematic viscosity of air

$\xi_{f}$ displacement of a fiber

p acoustic density of air

$\rho_{0}$ ambient density of air $\left(1.21 \mathrm{~kg} / \mathrm{m}^{3}\right)$

$P_{b}$ bulk density of material

$\rho_{f}$ density of ftber material $\left(1440 \mathrm{~kg} / \mathrm{m}^{3}\right)$

- viscous loss term, Eq. (A5)

$\omega$ radian frequency

$\omega_{f}$ resonant frequency of a fiber

\section{INTRODUCTION}

Acoustic propagation in porous materials has been studied since the time of Rayleigh. The early approach was to assume that the material was rigid and that the sound moved through small pores and lost energy through viscosity and heat conduction. 1,2 Later, the additional complexity of material motion was added. $^{3-6}$ since the material frame itself was flexible, an elastic wave could be sustained in the material and interact with the wave propagating through the atr. Thus, additional losses of acoustic energy were made through deformations of the material frame. Many of these studies have been done for porous materials, in general, while others have been based on modeling a specific type of material. Attenborough ${ }^{7,8}$ has reviewed most of these studies, so no attempt will be made here. This study will concentrate on the behavior of one particular type of fibrous material. 
Two characteristics of acoustic propagation in fibrous materiais will be considered in this report. The first is the effect of fiber motion on a material's acoustic behavior. In this context, the term "fiber motion" means that the fiber moves only under the influence of a passing acoustic wave. The ends of the flber are assumed to be fixed in space at the joints of the complex interconnection of fibers that make up the material. While Attenborough ${ }^{8}$ has expressed that no real material has shown the behavior described as fiber motion, Kawasima ${ }^{9}$ has analytically studied a model where fiber motion was assumed to be present in the material. In this report, fiber motion is used to describe some of the behavior seen in the data. When frame motion is discussed, it refers to the motion of the fibers under the influence of other fibers. An elastic, wavelike motion then occurs through the interconnected frame of the material. Most analysis has been done with this flexible frame approach, and much data have been collected to verify the analysis.

The second acoustic characteristic to be considered here results from the forming of a flbrous material into a blanket. When the fibers are manufactured into a blanket, the fibers are primarlly aligned in two-dimensional parallel planes, with some fibers arranged across these planes to hold the blanket together. This general alignment of the fibers creates an acoustic medium that is anisotropic, a characteristic of the medium where the acoustic propagation constant depends on the direction of propagation. Inside a flbrous material, the acoustic propagation constant depends on whether the sound is propagating parallel to the planes into which the fibers are arranged or whether the sound is propagating normal to these planes.

This study considers a fibrous bulk material called Kewlar. When it is used as a lining for wind tunnel test sections and for aircraft engine inlets, this materlal can withstand the severe environmental conditions that may occur 
without breaking down and dispersing in the flow. Kevlar has also been the subject of previous work, ${ }^{10-12}$ the results of which are used for compartson with the results of this study.

Data consisting of normal impedance measurements were taken from a series of single-density Kevlar samples, all with the same dimensions. The densities ranged from 4.6 to $67 \mathrm{~kg} / \mathrm{m}^{3}$, and data were taken at identical densities in both directions of sound propagation: normal to the fibers and parallel to the fibers. After a description of the experimental apparatus and procedure, the results for the normal fiber measurements and the parallel fiber measurements are shown and compared in terms of the normal absorption coefficients. This is followed by descriptions of the models of Hersh and Walker ${ }^{10}$ and of Kawasima, ${ }^{9}$ which are compared with data. Finally, the two models are combined to obtain an improved model for the normal fiber measurements.

\section{EXPERIMENTAL APPARATUS}

An acoustic duct, originaliy described in Ref. 13, was modifled for use as an impedance tube. 14 As shown in Fig. 1 , one end was closed off by a steel plate, and a 120-W compression driver with an acoustic horn was attached to the other end. The rectangular duct had inside dimensions of 3.81 by $10.16 \mathrm{~cm}$. The plane wave cutoff for these dimensions was approximately $1700 \mathrm{~Hz}$, which set the upper frequency limit of the measurements. To allow access to the interior, the top of the duct was made of removable plate sections. In one of these duct plates, two $0.64-\mathrm{cm}$ condenser microphones were mounted with a $3.81-\mathrm{cm}$ separation.

The measurements were based on the two-microphone transfer function technique described by chung and Blaser. ${ }^{15}$ with the assumption that the microphones measured the sound at a point, the microphone outputs were sent to a two-channel fast Fourler transform analyzer, which calculated the transfer 
function between those two points in the duct. Upon completion of this measurement, the two microphone systems were switched in position, and the measurement was repeated. This switching procedure resulted in two transfer functions, which were used to calculate a geometric average transfer function that was corrected for any gain and phase difference between the two microphone systems.

In addition to the measurement technique, considerations were given to minimizing blas and random errors. 16 The bias errors were minimized by locating the microphones close to the sample and by using a small analysis bandwidth. The distance of the microphone farthest from the sample was $11.18 \mathrm{~cm}$, and the analysis bandwidth was $5 \mathrm{~Hz}$. The random errors were minimized by maintaining a high coherence between the acoustic source and the microphone signals. This is difficult to do at very low frequencies and when the microphone spacing equals a half wavelength. The coherence was always greater than 0.99 for frequencies of $140 \mathrm{~Hz}$ and above. The microphone spacing was not a concern since the half-wavelength frequency was about $4.5 \mathrm{kHz}$, well above the frequency range of the measurements.

The Kevlar samples were cut from a low-density blanket in the form of a batting. The fibers were layered and lightly needled to hold the batting together. In addition, the batting had been treated with Zepel, a fluid repellant. The nominal specifications for the batting were a density of $6.4 \mathrm{~kg} / \mathrm{m}^{3}$ and a thickness of $2.54 \mathrm{~cm}$. Each piece was cut sightly less than the cross-sectional size of the duct to minimize any binding or clamping of the material at the duct walls.

After being weighed, the individual samples were placed through an opening in the top of the duct into a sample holder, a 4-mesh screen attached to the hard walls near the end of the duct, which held the samples in place against 
the hard end of the duct. With the screen in place, the sample holder was $3.81 \mathrm{~cm} \mathrm{high} \mathrm{by} 10.16 \mathrm{~cm}$ wide by $10.16 \mathrm{~cm}$ deep. An example of the sample nolder setup for measurements with the fiber planes normal to the direction of sound propagation (referred to as normal fiber measurements) is shown in Fig. $2(a)$. When measurements were made with the fiber planes parallel to the direction of sound propagation (parallel fiber measurements), the samples set up for the normal fiber measurements were taken out and rotated $90^{\circ}$, as shown in Fig. 2(b). This arrangement allowed both the normal and the parallel fiber measurements to be taken with the same samples, the same sample holder volume, and the same density. At the lowest density, the samples were 1ightly expanded to f1ll the volume of the sample holder. Subsequently, to increase the density, more individual samples were compressed into the volume of the sample holder. Thus, the variation in density ranged from 4.6 to $67 \mathrm{~kg} / \mathrm{m}^{3}$.

\section{RESULTS FROM MEASUREMENTS}

The transfer function data were used to calculate the specific impedances and the normal absorption coefficients for all the samples that were measured. These results, summarized in terms of the normal absorption coeffictent, are shown in Fig. 3 for the parallel fiber measurements and in Fig. 4 for the normal fiber measurements. Each figure shows how the absorption coefficient curves ( $\alpha_{n}$ versus frequency) evolve as a function of density, which is labeled on the third axis of the figures. The density is lowest at the front of the figure and increases to the highest density at the back of the figure. The frequency range for all the data begins at $140 \mathrm{~Hz}$ and ends at $1500 \mathrm{~Hz}$.

The absorption coefficient curves for the parallel fiber measurements, shown in Fig. 3, are smooth with gradual changes taking place as a function of frequency and density. The primary absorption mechanisms are viscous losses across the fibers and heat transfer effects between the air and the fibers. 
In comparison to the parallel fiber data, the normal fiber data, shown in Fig. 4, have a resonance present in the data. This resonance is especially apparent in the higher density absorption coefficient curves, where a sharp peak is present in the curves. When the structure of the material is considered, this resonance is attributed to fiber motion. The viscous drag and the pressure gradient across the length of a normal fiber create enough force to laterally displace the fiber. In the case of the parallel fibers, the viscous drag and pressure gradient forces created along a fiber are not enough to cause the flbers to compress or buckle.

The results for the normal flber measurements are subject to different interpretations. At first inspection, it looks as if, as the density increases, the broad peak in the lowest density curve is evolving into the sharp peak in the highest density curve. It will be shown that this is not the correct interpretation and that the evolution of the sharp peak, which is attributed to a fiber resonance, also creates the dip in the lower density curves at the lower frequency end. The fiber resonance peak occurs at a frequency just above this dip, and it is broader and lower in amplitude at the lower densities on this plot; therefore, it is not clearly visible. As the density increases, the fiber resonance peak becomes higher and sharper, and it is always next to the dip. As shown, the dip and then the peak gradually move to a higher frequency as the density increases.

The data from the normal and parallel fiber measurements show that the material is anisotropic. The first obvious difference is the apparent presence of fiber motion when the sound propagates normal to the fiber direction. The second difference in the two directions is seen in the overall levels of absorption. By ignoring the normal fiber resonance and by considering the broad shape and level of the normal fiber and parallel fiber 
absorption coefficient curves, a comparison over the range of denstities measured can be made. At the lowest densities, the parallel fiber curves are at the same level or lower than the absorption coefficient curves for the normal fiber data. For example, in Fig. 3 the lowest density sample has absorption coefficients such that $0.16<\alpha_{n}<0.67$, and in Fig. 4 for the same density, $0.16<\alpha_{n}<0.78$. As the density increases, both sets of data shift unt11, at the highest density, the parallel fiber absorption coefficient curve is 3.5 to 14 percent higher than the normal fiber curve. Others ${ }^{2,17}$ have made similar measurements of absorption in materials where the results were dependent on the direction of sound propagation through the material. As in this study, the materials were made in sheets, with the fibers arranged in planes parallel to the face of the sheet. With higher density materials than that used here, their results showed that the absorption wa higher in the material when the sound propagated parallel to the plane of the fibers. This is consistent with the results shown in Figs. 3 and 4 .

\section{FIBROUS MATERIAL MODELS}

\section{Rigid Fiber Model}

Hersh and Walker ${ }^{10}$ developed a model to describe the acoustic behavior of fibrous bulk material. It is based on empirical relations derived from work done on pressure drop and energy transfer across bundles of circular cylinders or fibers. Because it assumes that the fibers are rigid, the model does not consider frame motion or fiber motion. This model is useful, however, since it describes the general behavior of Kevlar and it includes both parallel and normal fiber terms.

After the development of the empirical relations, the une-dimensional equations for continuity, momentum, and state are given in the following form for a differential volume of the material, where $\omega d^{2} / v<1$ : 


$$
\begin{aligned}
\frac{\partial \rho}{\partial t} & =-\rho_{0} \frac{\partial u}{\partial x} \\
\rho_{0} \frac{\partial u}{\partial t} & =-\frac{\partial p}{\partial x}-\sigma u \\
p & =c^{2} e^{\rho}
\end{aligned}
$$

All the varlables are acoustic quantities for air, and their definitions are given in the List of Symbols. The viscous loss term $\sigma$ and the effective propagation velocity $c_{e}$ are derived in appendix $A$. The effective propagation velocity through the porous material takes into account the effects of heat transfer between the air and the matertal.

Combining Eqs. (1) to (3) and assuming that all acoustic quantities are proportional to $\exp (1 \omega t-k x)$, we can get the wave equation and subsequently the propagation constant.

$$
k^{2}=1\left(\frac{\omega}{c_{e}}\right)^{2}\left(\frac{\sigma}{\rho_{0} \omega}+1\right)
$$

The characteristic impedance for the material is defined as the ratio of the pressure wave traveing in one direction to the volume velocity in the same direction, $W=p /(u H)$. From Eqs. (2) and (4), the normalized characteristic Impedance of the porous material is found to be

$$
\frac{W}{\rho_{0} c_{0}}=\frac{\omega}{c_{0}} \frac{\left(\frac{\sigma}{\rho_{0} \omega}+1\right)}{H K}=\frac{c_{0}}{\omega}\left(\frac{c_{e}}{c_{0}}\right)^{2} \frac{k}{1 H}
$$

The final step to determine the surface impedance of the material with a rigid backing requires the following boundary conditions at the surface:

$$
\begin{aligned}
& p^{\prime}=p \\
& u^{\prime}=H u
\end{aligned}
$$

The first equation has pressure continuous across the boundary, and the second equation has mass flux continuous across the boundary. With the additional 
condition that $u=0$ at the rigid boundary, the normalized impedance for a sample with finite depth $L$ is

$$
\frac{Z}{\rho_{0} c_{0}}=\frac{W}{\rho_{0} C_{0}} \operatorname{coth}(k L)
$$

and the normal absorption coefficient is

$$
a_{n}=1-\left|\frac{\frac{z}{p_{0} c_{0}}-1}{\frac{Z}{p_{0} c_{0}}+1}\right|^{2}
$$

A comparison between the parallel fiber data and the original model of Hersh and Walker using only the parallel flber viscous loss term is shown in Fig. 5 for the absorption coefficient, the specific acoustic resistance, and the specific acoustic reactance. The figure includes measured data (line with circles), results from the model (solid line), and results from a modification of the model (dashed line) to be described later in this section. In this sample of the data, the comparison is quite good throughout most of the measured density range. The model specific resistance has larger deviations from the data than the reactance at the higher densities. At lower densities, both resistance and reactance show their greatest deviation from the data at the higher frequencies. This is especially evident in the normal absorption coefficient plot at the lowest density. The absorption coefficlent is sensitive to small changes in resistance at small values of resistance. Thus, the model underpredicts the absorption.

Frame flexibility, which is not considered in any detail in this study, is another factor that appears to affect the results shown in Fig. 5 . As mentioned in the Introduction, this is the case where the material frame supports an elastic wave which interacts with the acoustic vave in the air. Kosten and Janssen ${ }^{18}$ have shown for a general porous flexible material that frame flexibility is important at low frequencies. Their results show that at 
some low frequency the absorption coefficient for the flexible frame material peaks at a higher level than the absorption coefficient for the same material with a rigid frame. As the frequency increases, the absorption coefficients for the two frames tend towards agreement. An example of this behavior is seen in Fig. 5(b). The experimental data (line with circles), which is assumed to include frame flexibllity effects, has peak absorption at about $850 \mathrm{~Hz}$. This absorption is higher than that shown for the rigid fiber model represented by the solid line. The two curves, then, tend towards agreement as the frequency increases. Similar behavior is seen in Figs. $5(c)$ and $5(d)$.

Since the model of Hersh and Walker is based on some empirtcal correlations, an attempt was made to see if any improvements could be made in the model by varying the fit parameters within the correlation, specifically the parallel fiber viscous loss term originally given by Hersh and Walker as

$$
f_{p}(1-H)=1.0\left[3.94(1-H)^{0.413}\left[1+27(1-H)^{3}\right]\right]
$$

The term $f_{p}(l-H)$ was used as a fit parameter to adjust the model impedance to best fit the data impedance for each density. The results of this fit are shown in Fig. 6. The fit for data below $1-H=0.02$, or a bulk density of about $29 \mathrm{~kg} / \mathrm{m}^{3}$, is scattered, and no fit equation comparable to Eq. (9) is possible. However, the fit data above this point do provide a good correlation represented by the equation

$$
f_{p}(1-H)=1.8\left[3.94(1-H)^{0.5}\left[1+27(1-H)^{3}\right]\right]
$$

When this fit is used in the acoustic model, the results are as shown in Fig. 5. The lack of signiflcant change between the originai parallel fiber model (Eq. (9)) and the modifled model (Eq. (10)) when compared with the data is most likely due to the lack of inclusion of frame flexibility effects. This is especially evident at the lower densities where, as shown in Fig. 6 , the 
fit of $f_{p}(1-H)$ did not agree with the rigid fiber correlations given by Eq. (9) or Eq. (10).

Comparison between the normal fiber model of Hersh and Walker and the data is shown in Fig. 7 for the absorption coefficient, the specific acoustic resistance, and the specific acoustic reactance. The trends in the data are similar to the model; however, the model generally underpredicts the measured impedance. Also, the model shows no indications of the resonances seen in the three higher densities in Fig. 7. The correlation for the normal fiber viscous loss is given by

$$
f_{n}(1-H)=0.44\left[16(1-H)^{0.5}\left[1+14.75(1-H)^{3}\right]\right]
$$

Its similarity to Eqs. (9) and (10) shows that the expected behavior of the normal fiber model is the same as the behavior shown for the parallel fiber model. The difference would be due to the different levels of viscous loss. It is interesting to note that for $7-H<0.05$, which is the case for all the measured densities, $(1-H)^{3} \ll 1$ with the result that Eq. (11) is approximately equal to Eq. (10).

The works of Lambert ${ }^{11}$ and Smith and Parrott ${ }^{12}$ have shown data on the impedance of Kevlar samples that have the same characteristics as shown in Fig. 7. Lambert's data for a porosity of 0.94 and a sample depth of $12 \mathrm{~cm}$ showed a resonance at about $950 \mathrm{~Hz}$. He states that this may be evidence that the sample is vibrating and absorbing energy. Smith and Parrott took Impedance measurements for Kevlar with and without a Zepel fluid repellant treatment. Their data for 1-cm-thick Kevlar samples at a porosity of 0.94 showed a resonance between 700 to $800 \mathrm{~Hz}$. No other resonance was seen in the data out to $3.5 \mathrm{kHz}$. They attributed the resonance to the possibility of fiber motion. 


\section{Fiber Motion Model}

Kawasima ${ }^{9}$ developed a model that included the effects of fiber motion. He assumed that each fiber could be represented as a string fixed at both ends. To simplify the analysis, the string of length $\ell$ was modeled as a rigid bar with the center part of length qe vibrating linearly and with the end parts of total length $q(1-\ell)$ fixed. The vibrating force was the oscillating viscous fluid, and the restoring force was governed by Hooke's law. From a dynamical analysis comparing the vibrating string to the vibrating bar, $q$ was found to be equal to 0.817 . The following equations were developed:

$$
\begin{gathered}
\frac{\partial \rho}{\partial t}=-\rho_{0} \frac{\partial u}{\partial x}-\rho_{0} q \frac{1-H}{H} \frac{\partial u_{f}}{\partial x} \\
\rho_{0} \frac{\partial u}{\partial t}=-\frac{\partial p}{\partial x}-q \frac{1-H}{H} \frac{r}{v_{f}}\left(u-u_{f}\right)-(1-q) \frac{1-H}{H} \frac{r}{v_{f}} u \\
\rho_{f} \frac{\partial u_{f}}{\partial t}+\rho_{f} \omega_{f}^{2} \xi_{f}=-\frac{\partial p}{\partial x}-\frac{r}{v_{f}}\left(u_{f}-u\right)
\end{gathered}
$$

Equation (12) is the continuity equation. The change in mass in a differential volume is governed by both the movement of air and the movement of fibers. The latter is represented by the second term on the right side of the equal sign. This equation is derived in appendix $B$.

The momentum equation is shown in Eq. (13). It shows that the motion of an elemental mass of air is driven by the pressure gradient, with damping across both the fiber parts that move and those that are fixed. The viscous loss coefficient, given by the ratio $r / v_{f}$, is assumed to be the same for both moving and fixed portions of the fibers.

The third equation governs the fiber motion. The left side of Eq. (14) is a mass-spring equation for the fiber in the elemental volume, with the restoring force governed by the resonant frequency $\omega_{f}$. The forcing terms, 
shown on the right side of the equation, are due to the pressure gradient and the viscous drag on the fiber.

When the acoustic pressure and density are related by the adlabatic speed of sound in air $\left(p=c_{0}^{2} p\right)$. Eqs. (12) to (14) can be combined to derive a wave equation for the pressure. Thus, the propagation constant is determined to be

$$
k^{2}=1\left(\frac{\omega}{c_{0}}\right)^{2} \frac{N}{D}
$$

where

$$
\begin{gathered}
N=\left[\frac{1-H}{H} \frac{r / v_{f}}{\rho_{0} \omega}+1\right]\left[\frac{r / v_{f}}{\rho_{0} \omega}+1 \frac{\rho_{f l}}{\rho_{0}}\right]-q \frac{1-H}{H}\left(\frac{r / v_{f}}{\rho_{0} \omega}\right)^{2} \\
D=\left[\frac{r / v_{f}}{\rho_{0} \omega}+1 \frac{\rho_{f l}}{\rho_{0}}\right]+q \frac{1-H}{H}\left[\frac{1-H}{H} \frac{r / v_{f}}{\rho_{0} \omega}+1\right]+2 q \frac{1-H}{H} \frac{r / v_{f}}{\rho_{0} \omega} \\
\rho_{f l}=\rho_{f}\left[1-\left(\frac{\omega_{f}}{\omega}\right)\right]^{2}
\end{gathered}
$$

The characteristic impedance for the material in this case is defined by using the following equation for the volume velocity per unit area:

$$
\bar{u}=H u+q(1-H) u_{f}
$$

This equation shows that the volume velocity is affected by those fibers that move. The result is that, depending on the phase relationship between $u$ and $u_{f}$, the volume velocity is higher or lower than that which would be found in a rigid materlal having the same porsity. By using Eq. (16), the normalized characteristic impedance is found to be

$$
\frac{W}{\rho_{0} c_{0}}=\frac{\frac{p}{u}}{\rho_{0} c_{0}}=\left(\frac{c_{0}}{\omega}\right) \frac{k}{i H}
$$


Using the boundary conditions given in Eq. (6) and the additional fact that $u=u_{f}=0$ at the rigid boundary yields the specific acoustic impedance at the surface:

$$
\frac{Z}{\rho_{0} C_{0}}=\frac{W}{\rho_{0} C_{0}}\left[1+q \frac{I-H}{H} \frac{N^{\prime}}{D^{\prime}}\right] \operatorname{coth}(K L)
$$

where

$$
\begin{gathered}
N^{\prime}=\left[\frac{1-H}{H} \frac{r / v_{f}}{\rho_{0} \omega}+1\right]+\frac{r / v_{f}}{\rho_{0} \omega} \\
D^{\prime}=\left[\frac{r / v_{f}}{\rho_{0} \omega}+1 \frac{\rho_{f l}}{\rho_{0}}\right]+q \frac{1-H}{H} \frac{r / v_{f}}{\rho_{0} \omega}
\end{gathered}
$$

It should be noted that the ratio $N^{\prime} / 0^{\prime}$ equals the ratio between the fiber velocity and the air velocity $u_{f} / u$. The absorption coefficient is then calculated from the impedance by using Eq. (8). This model development is similar to that given by Ingard, ${ }^{19}$ except that material frame motion was used there instead of fiber motion.

In Kawasima's model, the viscous loss coefficient $r / v_{f}$ is computed for Stokes flow around a long ellipsoid of gyration. The term is a function of the length and diameter of the fiber, and not a function of frequency. No attempt was made in this study to calculate this term; it was used as a parameter to fit the model to measured data.

A comparison between Kawasima's model and the data is shown in Fig. 8 . The resistance, reactance, and absorption coefficient curves for both model and data follow the same behavioral trends. The obvious feature is the resonance due to fiber motion. The assumption that viscous loss is not a function of frequency is shown to be inaccurate, since the viscous loss coefficient must provide the loss at each frequency and be a damping term at the resonance frequency. The model provides insufficient damping at the 
resonance, and it is much less accurate in predicting impedance at the low frequencies.

\section{Comblned Model}

Two factors that contribute to the inaccuracy of Kawasima's model are the use of the non-frequency-dependent viscous loss coefficient $\mathrm{r} / \mathrm{v}_{f}$ and the use of the adiabatic speed of sound for the air inside the fibrous material. It is proposed here to modify Kawasima's model by replacing these two factors by the equivalent factors from the model of Hersh and Walker.

The first factor to replace is the viscous loss coefficient $r / v_{f}$. If there is no fiber motion, then $u_{f}=0$. Substituting this value into Eq. (13) and reducing results in

$$
\rho_{0} \frac{\partial u}{\partial t}=-\frac{\partial p}{\partial x}-\frac{1-H}{H} \frac{r}{v_{f}} u
$$

Comparing this momentum equation to Eq. (2) shows that for the two equations to be equivalent

$$
\frac{r}{v_{f}}=\frac{H}{1-H} \sigma
$$

Thus, the constant $r / v_{f}$ is replaced by a function that is dependent on both frequency and porosity.

The adlabatic speed of sound is the other factor to replace in Kawasima's model. This is done by using Eq. (3) to define the relationship between pressure and density. When the propagation constant and characteristic impedance are determined, the result of this change is to replace $c_{0}$ by $c_{e}$ in Eq. (15) and to multiply the right side of Eq. (17) by $\left(c_{e} / c_{0}\right)^{2}$. Thus, the effects of heat transfer between the air and the fibers have been taken into account.

The final calculations, then, for the specific impedance are done by using Eq. (18) with the proper substitutions: Eq. (20) is used to replace the 
viscous loss coefficient, and the modified Eqs. (15) and (17) are used for the propagation constant and the normalized characteristic impedance, respectively.

The results of calculations using this combined model are shown in Fig. 8 . The only factor unknown a priori in these calculations was the fiber resonant frequency $\omega_{f}$. All other factors were based on the original models of Hersh and Walker 10 and Kawasima. ${ }^{9}$ As shown in the figure, the calculated specific reactance agrees quite well with the data, but the model does underpredict the specific resistance. Factors such as losses due to internal damping of the fibers or due to fibers rubbing together and frame flexibility were not considered. This may have led to the inaccuracies in the model at the lower densities, at the lower frequencies, and at the resonant frequency.

\section{CONCLUDING REMARKS}

Experiments were conducted to study the acoustic behavior of a fibrous material. The fibers in this material were arranged such that the sound could propagate in a direction normal to the fiber arrangement or parallel to the fiber arrangement. This permitted an evaluation of the anisotropic acoustic characteristics of the material.

The results of the measurements were summarized in three-dimensional plots of absorption coefficient versus frequency as a function of the sample density. When the sound was propagating normal to the fibers, the measurements indicated a resonant condition, which was attributed to fiber motion. This resonance was shown to change in frequency as the density increased. When the sound was propagating parallel to the fibers, the measurements showed no indications of a fiber motion resonance. Other than the fiber motion effects, anisotropy was shown to exist over the rest of the frequency range of the measurements. This was shown by the level of absorption that took place. At low density, the parallel fiber absorption coefficlents were less than the normal fiber 
absorption coefficients. The opposite was true at the higher densities. There, the normal fiber absorption coefficients were less than the parallel fiber absorption coefficients.

Models were used to confirm these results. The parallel fiber measurements were compared with the parallel fiber model of Hersh and Walker. Though an attempt was made to improve the model by adjusting constants in the model, no significant improvement was obtained. For the normal fiber model, improvements were made by combining the model of Hersh and Walker with the model of Kawasima. This combined model accounted for the effects of fiber motion, and it accounted for the frequency and porosity dependence of the viscous loss term and of the heat transfer parameter. Results for this model were found to agree with the data except at the lower densities, where frame flexibility, which was not included in any of the models, had a large effect. 


\section{APPENDIX A - DERIVATION OF EMPIRICAL PARAMETERS}

\section{Viscous Loss Term o}

The one-dimensional pressure drop per unit distance across a bunde of fibers numbering $N$ is

$$
\frac{\Delta p}{\Delta x}=-\frac{N}{\Delta x A} D
$$

where $D$ is the fluctuating drag of each fiber and $A$ is the cross-sectional area of the duct. The minus sign assures that the pressure decreases across the bundle of fibers. The fluctuating drag is given by the product of the cylindrical area $A_{f}$ of a flber and the area-averaged fluctuating shear stress TAV

$$
D=A_{f}^{\top} A V
$$

where $\tau_{A V}$ is approxtmated by

$$
\tau_{A V}=\frac{\mu f u}{d}
$$

The function $f$ is a nondimensional term that accounts for the average drag of a circular cylinder in a bundle of cylinders. It is a function of porosity. Using the definition of porosity as the ratio of the volume of air to the total volume of the material yields the following equation:

$$
1-H=\frac{N v_{f}}{\Delta x A}
$$

Combining Eqs. (A2) to (A4) into Eq. (A1) yields

$$
\frac{\Delta p}{\Delta x}=-\left(\frac{4 \mu}{d^{2}}\right)(1-H) f u=-\sigma u
$$

where the following relation was used for the ratio between the circular area of a cylinder and its volume:

$$
\frac{A_{f}}{v_{f}}=\frac{4}{d}
$$

The viscous loss term a has been defined in Eq. (A5). It is made nondimensional by dividing by $\rho_{0}$ and $\omega$. Thus, 


$$
\frac{\sigma}{\rho_{0} \omega}=4 \frac{\mu}{\rho_{0} \omega d^{2}}(1-H) f=4\left(\frac{v}{\omega d^{2}}\right)(1-H) f
$$

The function $f$ is defined from correlations derived by Hersh and Walker. 10 For parallel fibers, $f=f_{p}$ in Eq. (9); and for normal fibers, $f=f_{n}$ in Eq. (11).

$$
\text { Effective Propagation Velocity } c_{e}
$$

For a unit volume of material $\triangle \times A$, the rate of increase in energy per unit volume of air minus the net rate of energy out of the volume through the air must equal the energy flow from the fibers to the air per unit volume of air. This statement can be written as

$$
P_{0} C_{v} \frac{\partial \theta}{\partial t}-\frac{p_{0}}{P_{0}} \frac{\partial \rho}{\partial t}=-e
$$

Combining an equation for the heat flow

$$
Q=\text { hNA }_{f} \theta
$$

and the definition of the Nusselt number

$$
N u=\frac{h d}{k^{\prime}}
$$

we get

$$
Q=\frac{N u k^{\prime} N A_{f} \theta}{d}
$$

To put Eq. (AII) on a basis of per unit volume of air, we divide the equation by $\triangle X A H$. Then, by using Eqs. (A4) and (A6), an equation for $e$ is obtained:

$$
e=\frac{Q}{\Delta \times A H}=\frac{4 K^{\prime} N U}{d^{2}}\left(\frac{1-H}{H}\right) \theta
$$

Thus, with this equation, we can rearrange $E q .(A 8)$ to get

$$
\frac{\partial \theta}{\partial t}+\frac{K}{\rho_{0}} \theta=(r-1) \frac{T_{0}}{\rho_{0}} \frac{\partial \rho}{\partial t}
$$

Where

$$
\frac{P_{0}}{P_{0} C_{v}}=\frac{R T_{0}}{C_{v}}=(r-1) T_{0}
$$


and

$$
K=\frac{4 K^{\prime}}{d^{2} c_{V}}\left(\frac{1-H}{H}\right) N u
$$

Equation (A14) can be nondimensionalized as follows:

$$
\begin{aligned}
\frac{K}{\rho_{0} \omega} & =4\left(\frac{c_{p}}{C_{V}}\right)\left(\frac{K^{\prime}}{\mu C_{p}}\right)\left(\frac{\mu}{\rho_{0}}\right) \frac{1}{\omega d^{2}}\left(\frac{1-H}{H}\right) N u \\
& =\frac{4 Y}{\operatorname{Pr}}\left(\frac{v}{\omega d^{2}}\right)\left(\frac{1-H}{H}\right) N u
\end{aligned}
$$

where $\mathrm{Pr}$ is the Prandtl number for air. The correlation for $\mathrm{Nu}$ given by Hersh and Walker 10 is

$$
\mathrm{Nu}=1.0\left[5.4(1-H)^{0.5}\left[1+3.94(1-H)^{3}\right]\right]
$$

Equation (A13) may now be solved for $\theta$ by assuming harmonic motion $\exp (i \omega t)$

$$
\theta=\frac{i(Y-1) T_{0}}{\rho_{0}\left(\frac{K}{\rho_{0} \omega}+i\right)}
$$

The equation of state is given in its instantaneous form as

$$
\left(p_{0}+p\right)=\left(p_{0}+p\right) R\left(T_{0}+\theta\right)
$$

When only linear terms are retained, this equation becomes

$$
p=\rho_{0} R \theta+R T_{0} p
$$

and upon substituting in Eq. (A17), a relationship between $p$ and $p$ is obtained.

$$
p=c_{e}^{2}
$$

where

$$
c_{e}^{2}=R T_{0}\left[\frac{\frac{K}{\rho_{0} \omega}+1 Y}{\frac{K}{\rho_{0} \omega}+1}\right]
$$

Note that when $K / \rho_{0} \omega \gg 1$ (very low frequencles), $c_{e}^{2}=R T_{0}$, the isothermal speed of sound. Aiso, when $K / \rho_{0} \omega \ll 1$ (very high frequencies), $c_{e}^{2}=\gamma R T_{0}$, the the adtabatic speed of sound. 


\section{APPENDIX B - DERIVATION OF EQUATION (12)}

Equation (12) is derived from two continuity equations. The first continuity equation is for the air in the material, and the second continuity equation is for the fiber material.

$$
\begin{aligned}
& \frac{\partial}{\partial t}\left(\rho_{0}+\rho\right) H=-\rho_{0} H \frac{\partial u}{\partial x} \\
& \frac{\partial}{\partial t} \rho_{f}(1-H)=-\rho_{f} q(1-H) \frac{\partial u_{f}}{\partial x}
\end{aligned}
$$

Expanding these two equations and retaining only linear terms, we get

$$
\begin{gathered}
\rho_{0} \frac{\partial H}{\partial t}+H \frac{\partial \rho}{\partial t}=-\rho_{0} H \frac{\partial u}{\partial x} \\
\frac{\partial \rho_{f}}{\partial t}-\rho_{f} \frac{\partial H}{\partial t}-H \frac{\partial \rho_{f}}{\partial t}=-\rho_{f} q(1-H) \frac{\partial u_{f}}{\partial x}
\end{gathered}
$$

By assuming that the compressibility of the fiber material is very small compared to afr and may be neglected, then $\partial \rho_{f} / \partial t=0$ and Eq. (B4) becomes

$$
\frac{\partial H}{\partial t}=q(1-H) \frac{\partial u_{f}}{\partial x}
$$

Substituting Eq. (B5) into Eq. (B3) and rearranging, we get Eq. (12).

$$
\frac{\partial \rho}{\partial t}=-\rho_{0} \frac{\partial u}{\partial x}-\rho_{0} q \frac{1-H}{H} \frac{\partial u_{f}}{\partial x}
$$




\section{REFERENCES}

1. J.W.S. Rayleigh, The Theory of Sound (Dover, NY, 1945) Vol. II, 2nd ed., p. 328.

2. R.A. Scott, "The Absorption of Sound in a Homogeneous Porous Medium," Proc. Phys. Soc. London, 58, 165-183 (1946).

3. L.L. Beranek, "Acoustical Properties of Homogeneous, Isotropic Rigid Tiles and Flexible Blankets," J. Acoust. Soc. Am., 19, 556-568 (1947).

4. C. Zwikker and C.W. Kosten, Sound Absorbing Materials (Elsevier, NY, 1949).

5. M.A. 810t, "Theory of Propagation of Elastic Waves in a fluid-Saturated Porous Solld. I. Low-Frequency Range," J. Acoust. Soc. Am., 28, 168-178 (1956).

6. M.A. 810t, "Theory of Propagation of Elastic Waves in a Fluid-Saturated Porous Sol1d. II. Higher Frequency Range," J. Acoust. Soc. Am., 28, 179-191 (1956).

7. K. Attenborough, "The Influence of Microstructure on Propagation in Porous Fibrous Absorbents," J. Sound Vibr., 16, 419-442 (1971).

8. K. Attenborough, "Acoustical Characteristics of Porous Materials, " Phys. Rep., 82, 179-227 (1982).

9. Y. Kawasima, "Sound Propagation in a Fibre Block as a Composite Medium," Acustica, 10, 208-217 (1960).

10. A.S. Hersh and B. Walker, "Acoustic Behavior of Fibrous Bulk Material." AIAA Paper 80-0986 (1980).

11. R.F. Lambert, "Acoustical Properties of Highly Porous Fibrous Materials," NASA TM-80135 (1979).

12. C.D. Smith and T.L. Parrott, "An Experimental Study of the Effects of Water Repellant Treatment on the Acoustic Properties of Kevlar," NASA TM-78654 (1978). 


\section{ORIGNAL PAG S}

OF. POOR QUALITY

13. G.P. Succi, K.J. Baumeister, and K.U. Ingard, "Interaction of a Turbulent-Jet Noise Source with Transverse Modes in a Rectangular Duct," NASA TP-1248 (1978).

14. M.D. Dahl and E.J. Rice, "Measured Acoustic Properties of Variable and Low Density Bulk Absorbers," NASA TM-87065 (1985).

15. J.Y. Chung and D.A. Blaser, "Transfer Function Method of Measuring In-Duct Acoustic Properties. I. Theory," J. Acoust. Soc. Am., 杰, 907-913 (1980).

16. A.F. Seybert and B. Soenarko, "Error Analysis of Spectral Estimates with Application to the Measurement of Acoustic Parameters Using Random Sound Fields in Ducts," J. Acoust. Soc. Am., 69, 1190-1199 (1981).

17. A. Bokor, "Attenuation of Sound in Lined Ducts," J. Sound Vibr., $\underline{\underline{10}}$, $390-403(1969)$.

18. C. W. Kosten and J. H. Janssen, "Acoustic Properties of Flexible and Porous Materials," Acustica, 1, 372-378 (1957).

19. K. U. Ingard, "Locally and Nonlocally Reacting Flexible Porous Layers; A Comparison of Acoustical Properties," J. Eng. Ind., 103, 302-313 (1981).

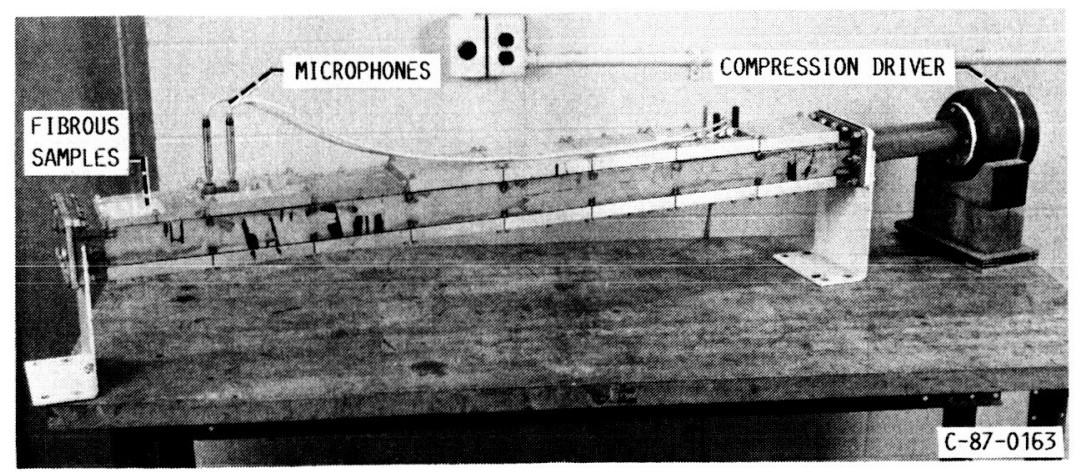

FiguRE 1. - ACOUSTIC IMPEDANCE MEASUREMENT DUCT. INSIDE DIMENSIONS, $3.81 \mathrm{BY}$ $10.16 \mathrm{~cm}$. 


\section{ORIGINAL PAGE IS \\ OF POOR QUALITY}

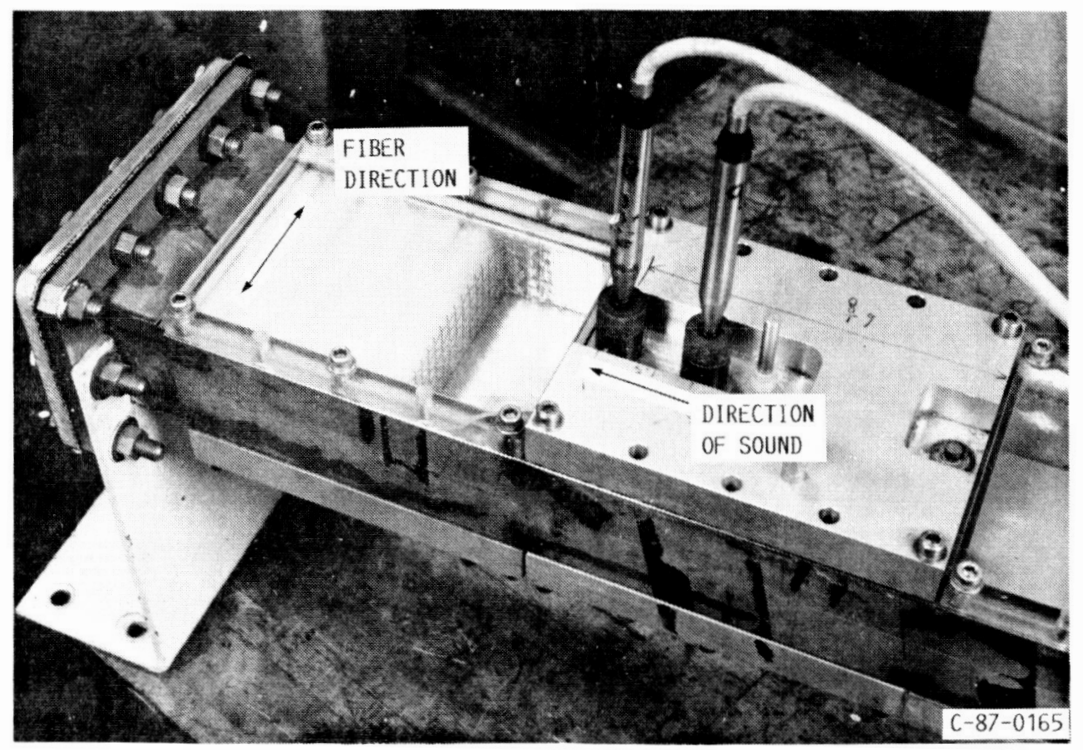

(A) FIBER DIKECIIUN NUKMAL IO DIRECTION OH SOUND PROPAGATION.

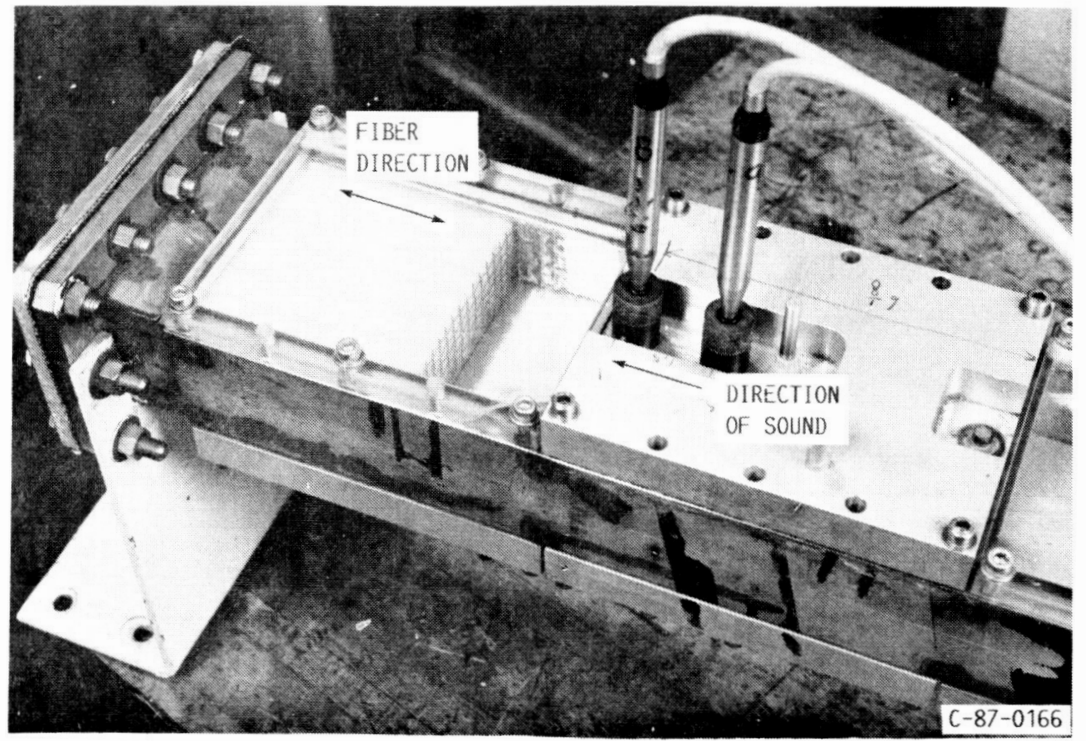

(B) FIBER DIRECTION PARALLEL TO DIRECTION OF SOUND PROPAGATION.

FIGURE 2. - MATERIAL SAMPLES PLACED IN DUCT. 


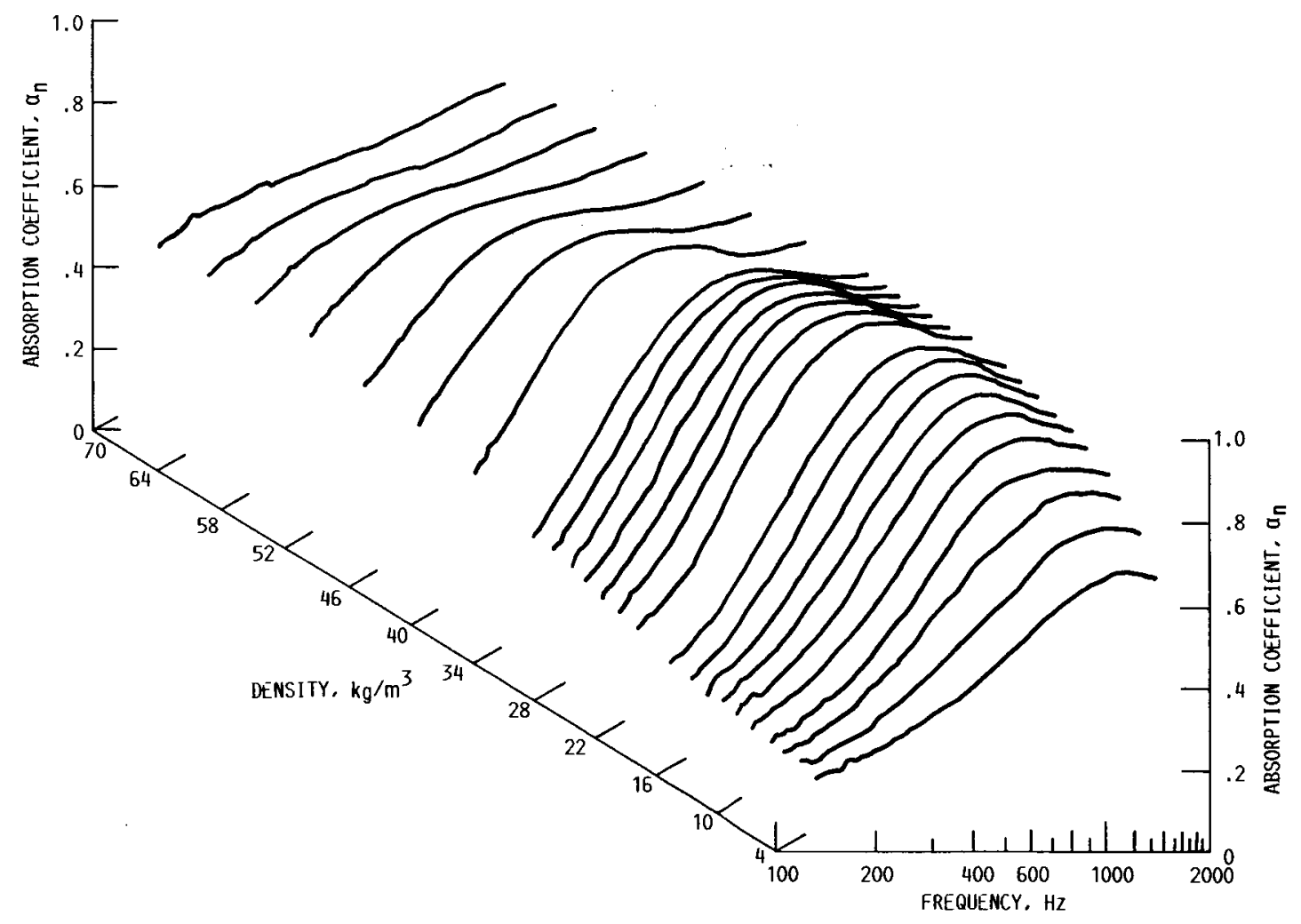

FIGURE 3. - NORMAL ABSORPTION COEFF ICIENT CURVES AS FUNCTION OF DENSITY FOR PARALLEL FIBER MEASUREMENTS.

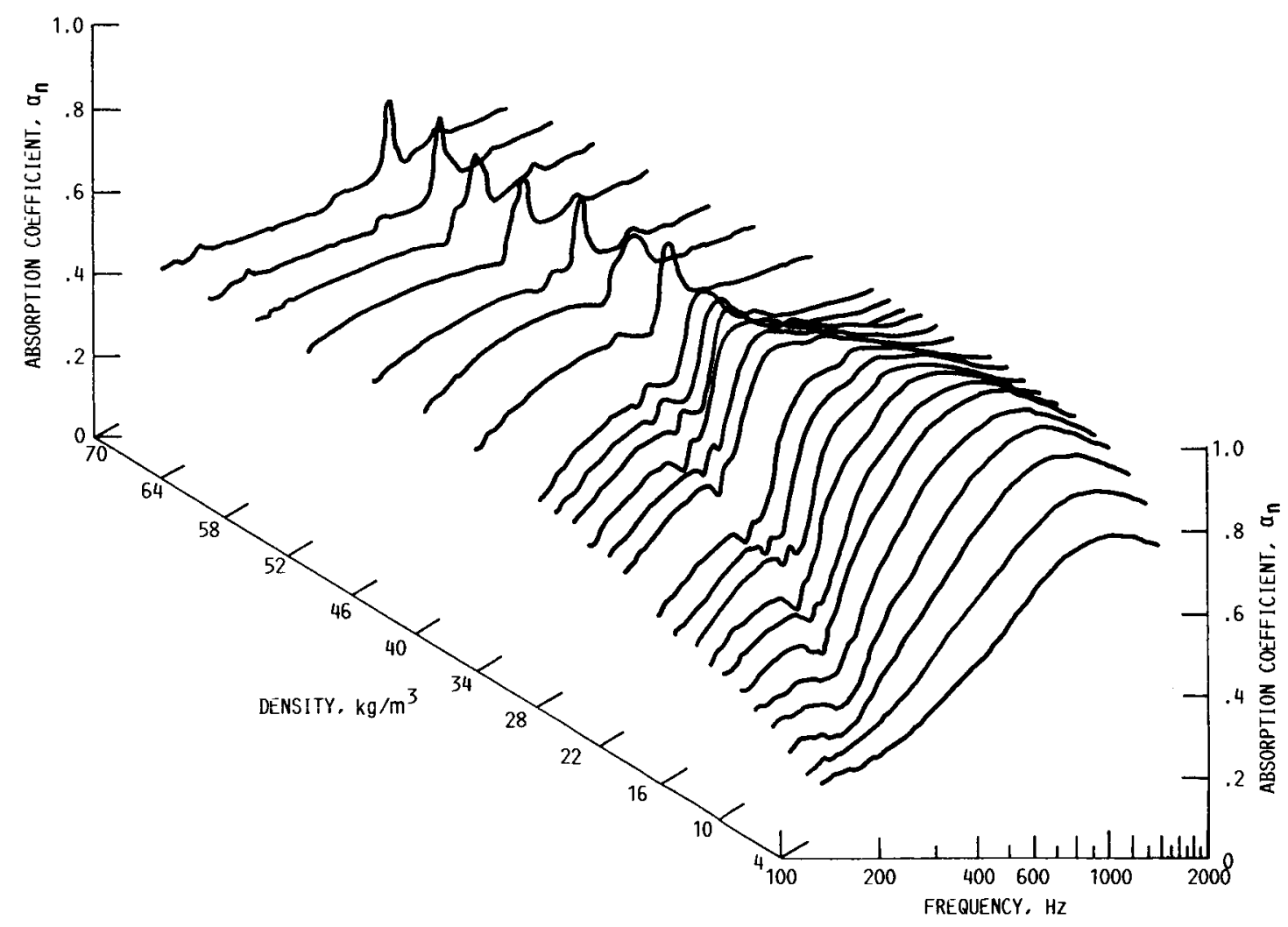

FIGURE 4. - NORMAL ABSORPTION COEFFICIENT CURVES AS FUNCTION OF DENSITY FOR NORMAL FIBER MEASUREMENTS. 

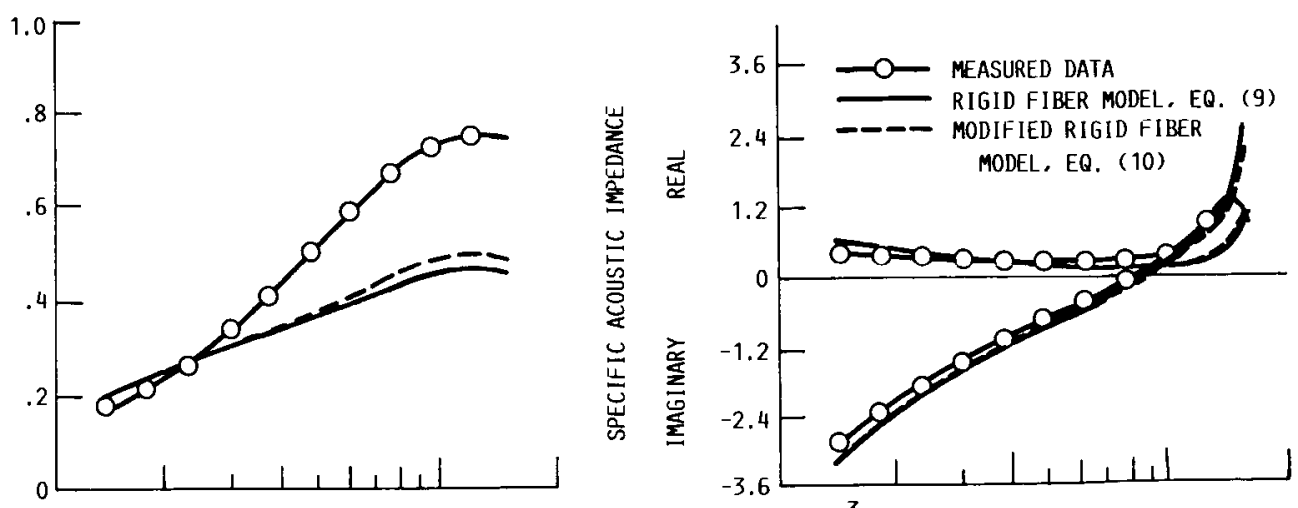

(A) BULK DENSITY $P_{b}, 6.1 \mathrm{~kg} / \mathrm{m}^{3}$.
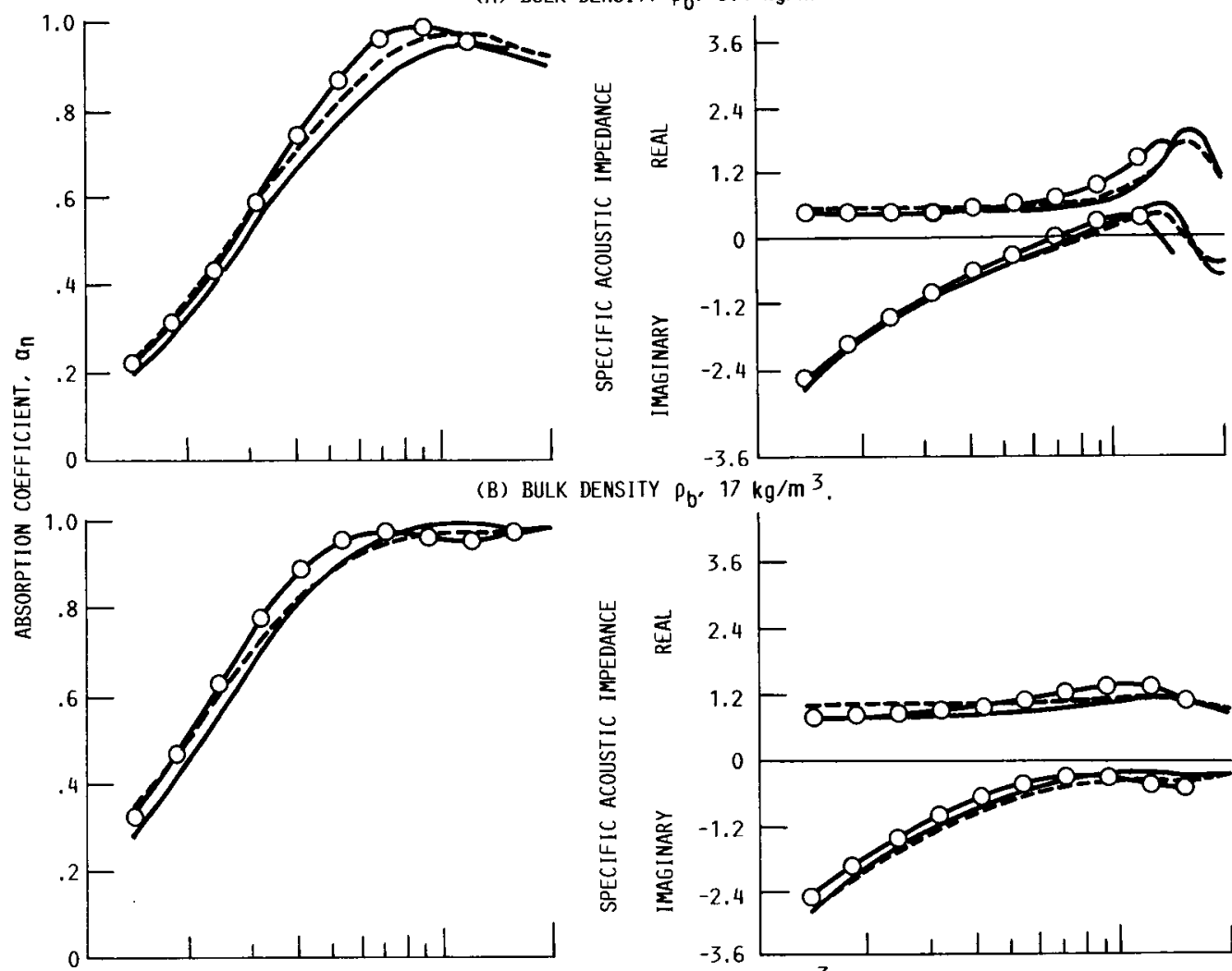

B) BULK DENSITY $\rho_{b}, 17 \mathrm{~kg} / \mathrm{m}^{3}$.
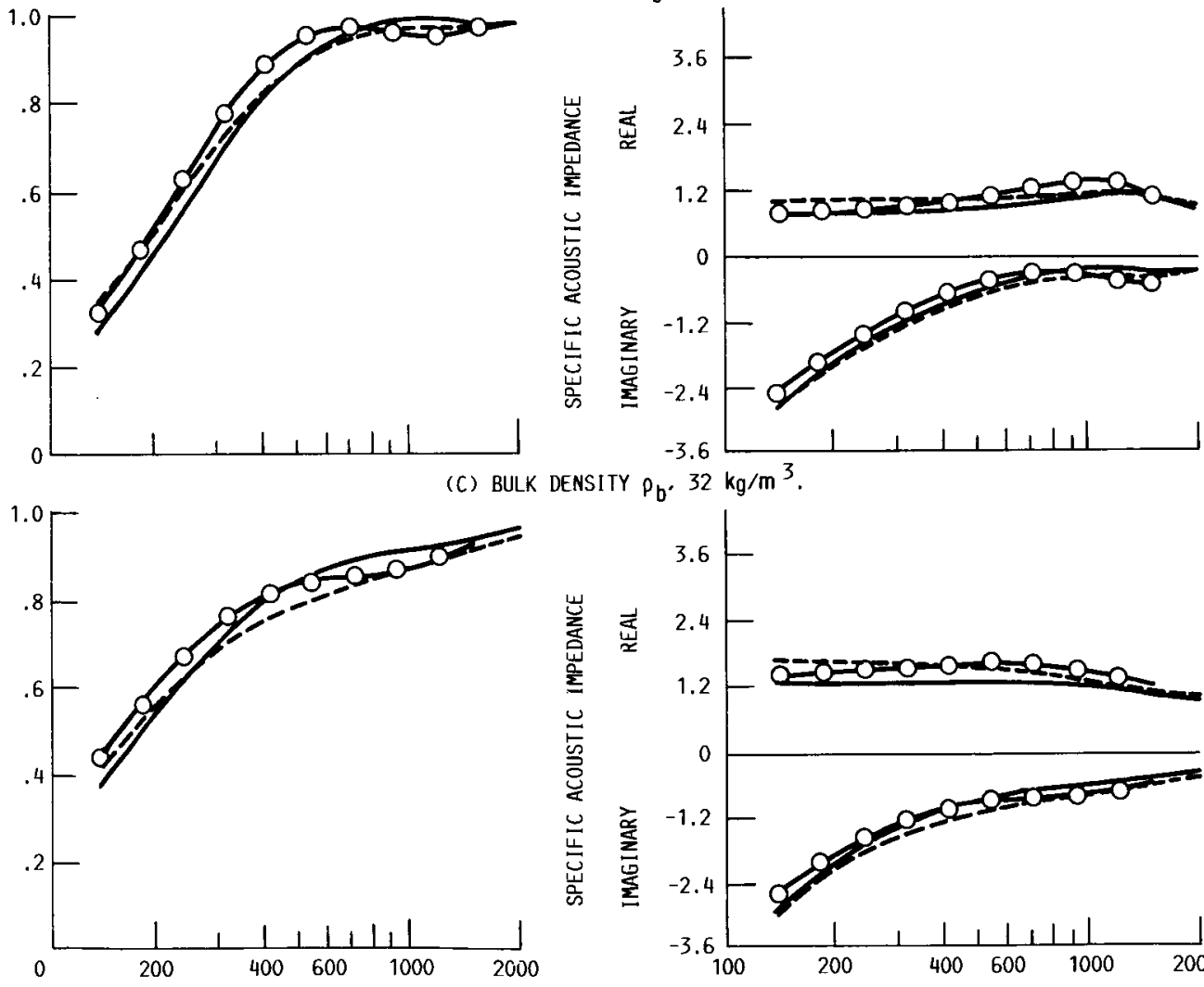

(C) BULK DENSITY $P_{\mathrm{b}} \cdot 32 \mathrm{~kg} / \mathrm{m}^{3}$.

(D) BULK DENSITY $P_{b}, 47 \mathrm{~kg} / \mathrm{cm}^{3}$.

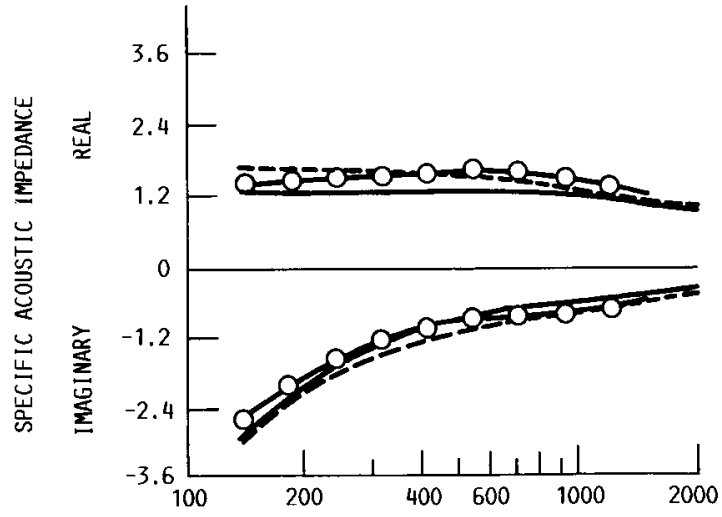

FREQUENCY, HZ

FIGURE 5 - EXAMPLE COMPARISONS BETWEEN PARALLEL FIBER MEASUREMENTS AND PARALLEL FIBER MODEL PREDICTIONS FOR NORMAL ABSORPTION COEFFICIENTS AND SPECIFIC ACOUSTIC IMPEDANCES. 


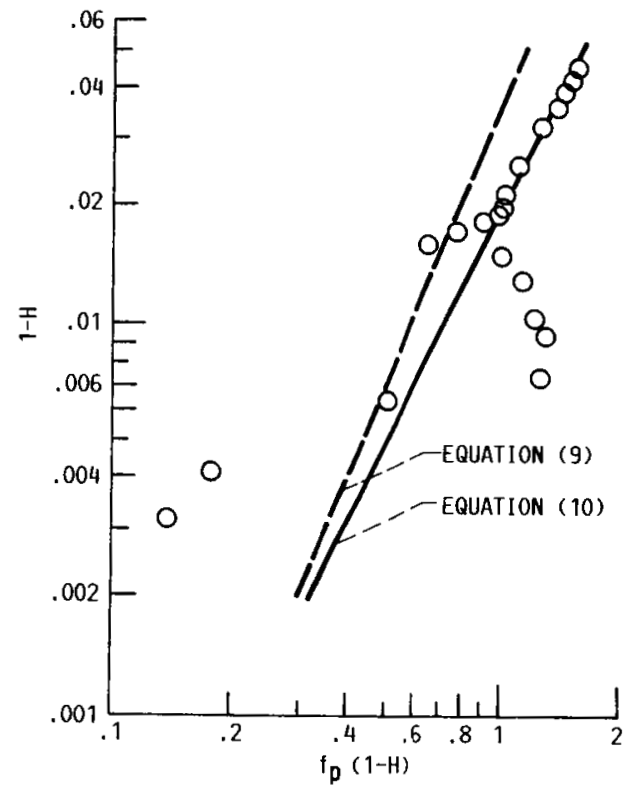

FIGURE 6, - RESULT OF FITTING EQ. (7) TO THE DATA WITH $f_{p}(1-H)$ AS FIT PARAMETER. 

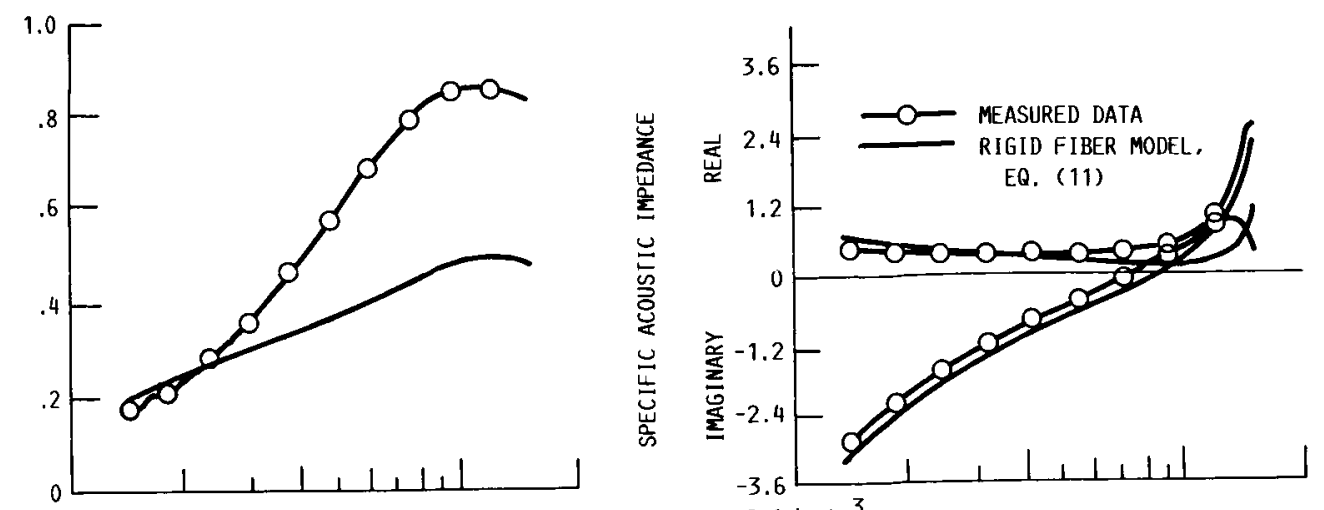

(A) BULLK DENSITY $\mathrm{P}_{\mathrm{b}}, 6.1 \mathrm{~kg} / \mathrm{m}^{3}$.
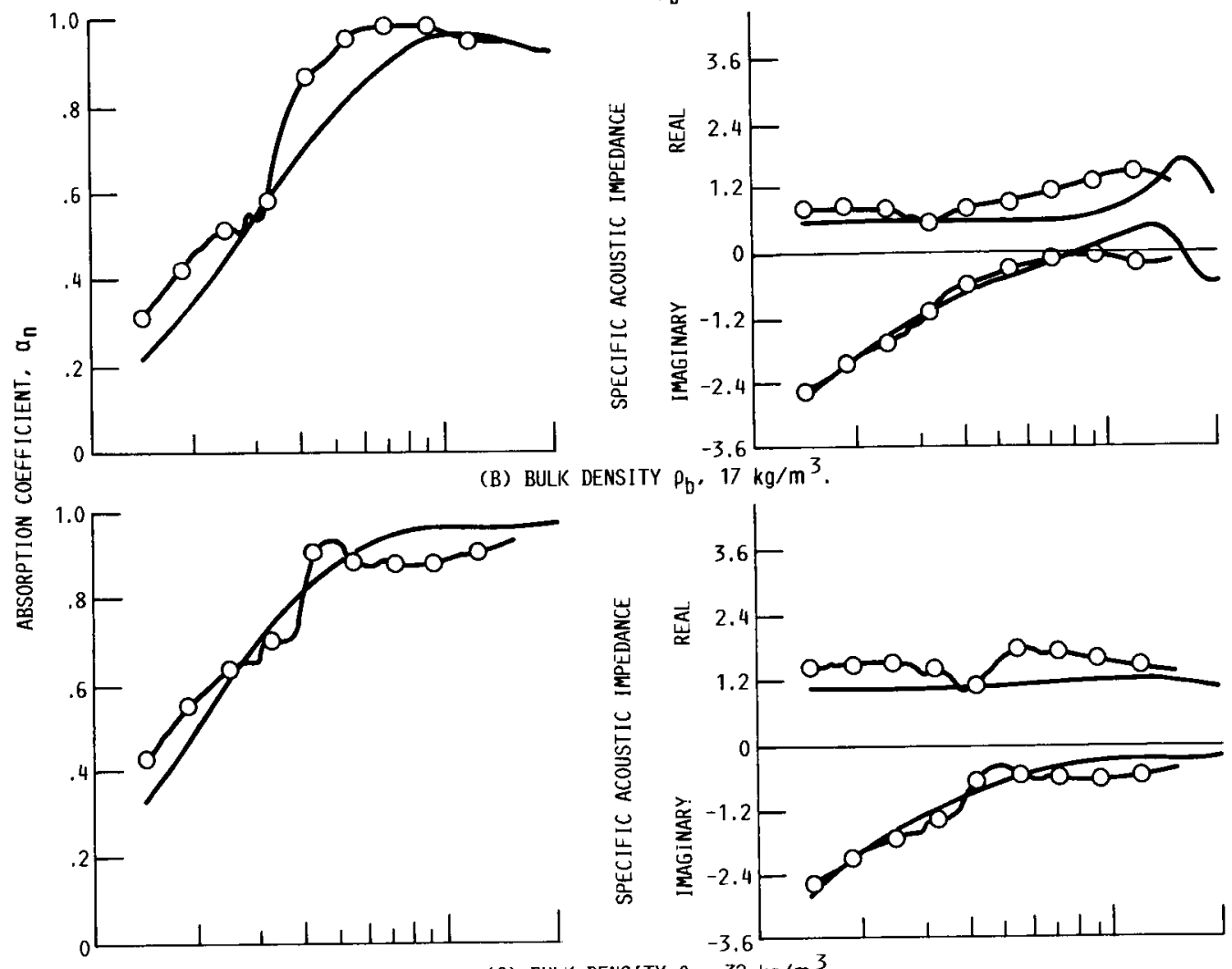

(C) BULK DENSITY $\rho_{\mathrm{b}}, 32 \mathrm{~kg} / \mathrm{m}^{3}$.
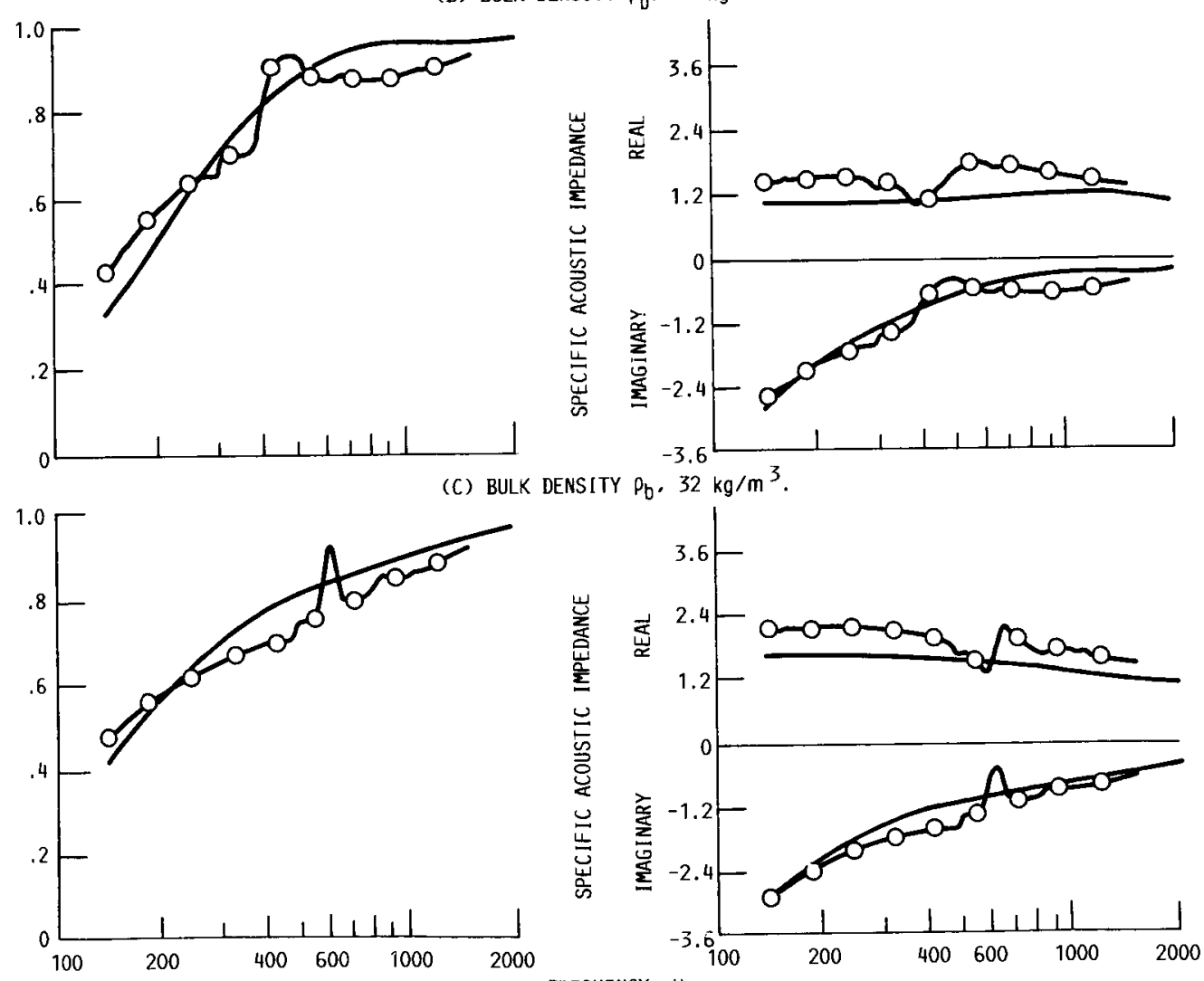

(D) BULK DENSITY $P_{b}, 47 \mathrm{~kg} / \mathrm{m}^{3}$.

FIGURE 7. - EXAMPLE COMPARISONS BETWEEN NORMAL FIBER MEASUREMENTS AND NORMAL FIBER MODEL PREDICTIONS FOR NORMAL ABSORPTION COEFFICIENTS AND SPECIFIC ACOUSTIC IMPEDANCES. 

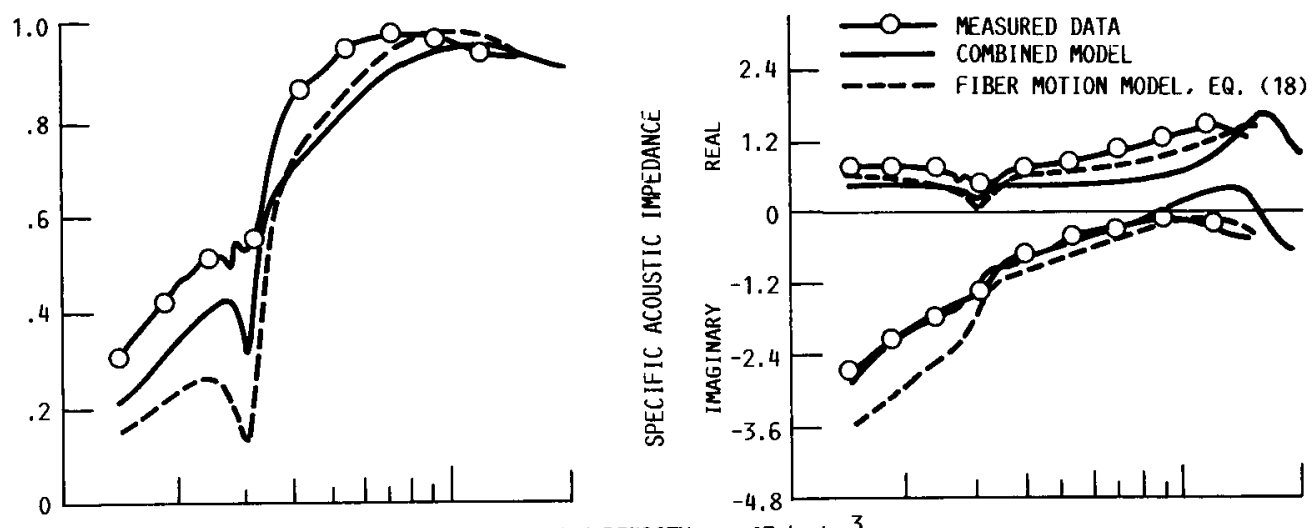

(A) BULK DENSITY $P_{b}, 17 \mathrm{~kg} / \mathrm{m}^{3}$.
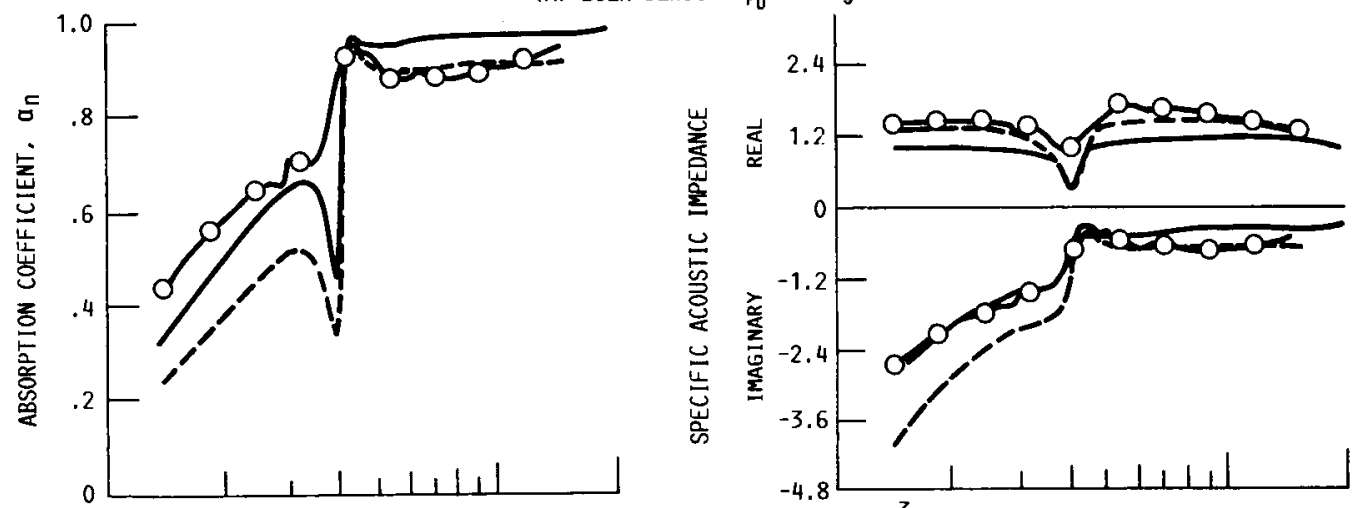

(B) BULK DENSITY $\rho_{b^{\circ}} .32 \mathrm{~kg} / \mathrm{m}^{3}$.
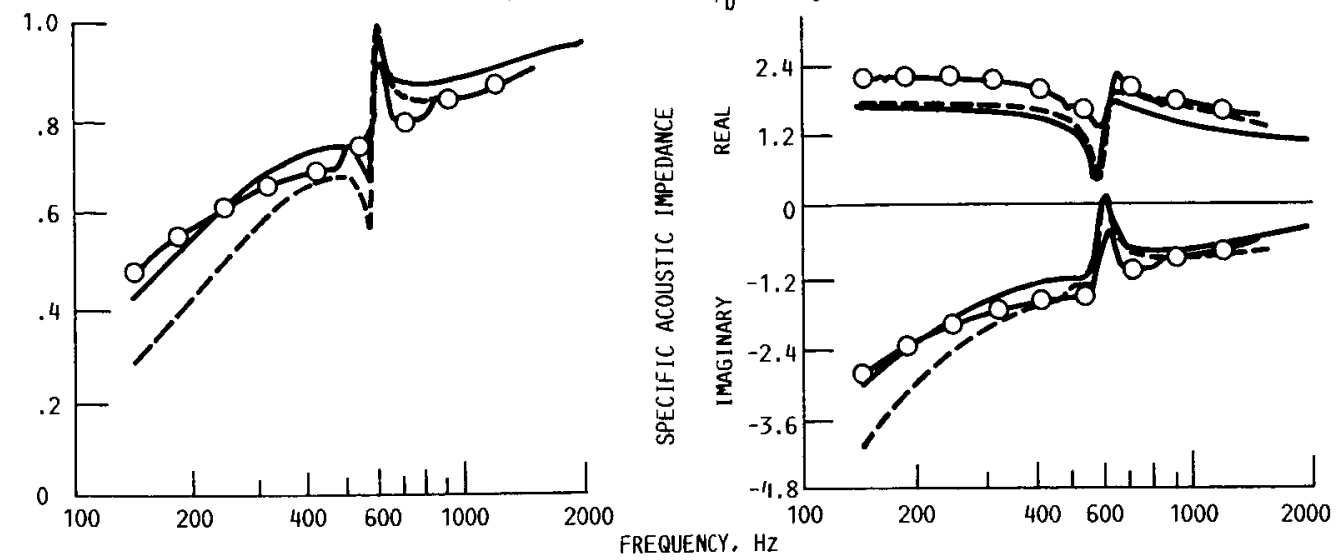

(C) BULK DENSITY $\rho_{b}, 47 \mathrm{~kg} / \mathrm{m}^{3}$.

FIGURE 8. - EXAMPLE COMPARISONS BETWEEN NORMAL FIBER MEASUREMENTS AND MODELS PREDICTING FIBER MOTION FFFECTS. 


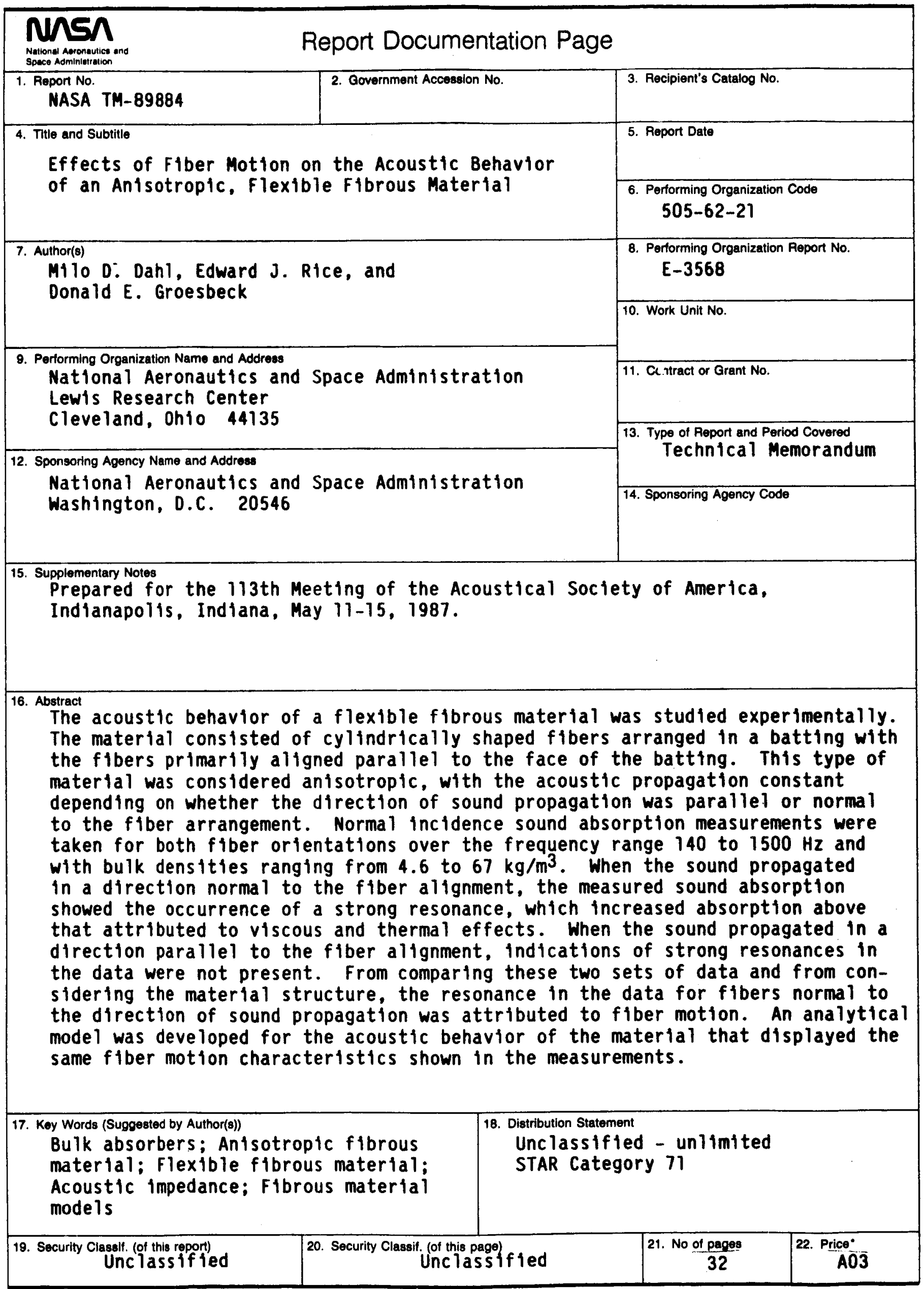

